\title{
The Effects of Interdot Spacing and Dot Size on the Performance of InGaAs/GaAs QDIBSC
}

\author{
Sayeda Anika Amin, ${ }^{1}$ Md. Tanvir Hasan, ${ }^{2}$ and Muhammad Shaffatul Islam ${ }^{3}$ \\ ${ }^{1}$ Department of Electrical and Electronic Engineering, American International University-Bangladesh (AIUB), \\ Dhaka 1213, Bangladesh \\ ${ }^{2}$ Department of Electrical and Electronic Engineering, Jessore University of Science and Technology (JUST), Jessore 7408, Bangladesh \\ ${ }^{3}$ Department of Electrical and Electronic Engineering, World University of Bangladesh (WUB), Dhaka 1205, Bangladesh
}

Correspondence should be addressed to Sayeda Anika Amin; anika.amin.30@gmail.com

Received 2 June 2017; Accepted 24 September 2017; Published 26 October 2017

Academic Editor: Srinivas Devayajanam

Copyright (c) 2017 Sayeda Anika Amin et al. This is an open access article distributed under the Creative Commons Attribution License, which permits unrestricted use, distribution, and reproduction in any medium, provided the original work is properly cited.

\begin{abstract}
$\mathrm{In}_{0.53} \mathrm{Ga}_{0.47} \mathrm{As} / \mathrm{GaAs}$-based quantum dot intermediate band solar cells (QDIBSCs) have been designed and optimized for the next generation photovoltaic technology. The wave behavior of charge carriers inside the dot and their barrier have been analyzed with different dot sizes and interdot spacing. The device characteristics such as short circuit current density, $J_{\text {sc }}$, open circuit voltage, $V_{\mathrm{oc}}$, and conversion efficiency, $\eta$, have been evaluated. Based on the behavior of electron wave function, it is found that varying the dot spacing leads to a change in the IB width and in the density of states, whereas varying the size of dots leads to a formation of a second IB. For a fixed dot spacing, two ranges of dot sizes vary the number of IBs in $\mathrm{In}_{0.53} \mathrm{Ga}_{0.47} \mathrm{As} / \mathrm{GaAs}$ QDIBSC. Smaller dots of a size ranging from $2 \mathrm{~nm}$ to $5 \mathrm{~nm}$ form a single IB while larger dots of a size ranging from $6 \mathrm{~nm}$ to $9 \mathrm{~nm}$ can produce 2 IBs. The efficiency of 2 IBs close to 1 IB suggests that formation of multiple IBs can possibly enhance the device efficiency.
\end{abstract}

\section{Introduction}

The concept of an intermediate band solar cell (IBSC) has created enormous interests to replace the traditional solar devices. The major reason behind this is the maximum theoretical limit of 63.2\% [1] calculated by Luque and Martí which outstrips the single-junction Shockley-Queisser limit [2]. For fully concentrated light, this efficiency occurs when the largest bandgap is $1.93 \mathrm{eV}$ under certain assumptions [1]. The intermediate band (IB) is attained by introducing an IB material between two selective contacts of $p$ type and $n$ type [3] which split the energy bandgap $E_{g}$ into two subbandgaps. This allows the formation of additional electron-hole pairs from the absorption of two subbandgap energy photons [4]. Low-dimensional semiconductor quantum dots (QDs) positioned in the absorption region of a p-i-n solar cell have been proved to be pertinent to realize IBSC concept $[1,5,6]$. The tight and regular arrangements of QDs in a quantum dot intermediate band solar cell (QDIBSC) lead to the formation of an IB or a superlattice miniband that is well separated in energy from the higher order states.

The InAs/GaAs and InGaAs/GaAs quantum dot systems have become the most canonical systems for studying the concept of IBSCs $[7,8]$. The GaAs has reached an efficiency of $28.8 \%$ as reported by Green et al. [9] which is quite close to its Shockley-Queisser limit. However, irrespective of the potential to achieve high efficiency, reports of QDIBSCs have shown significantly low efficiencies. An efficiency of $18.7 \%$ is achieved under air mass 1.5 condition with an antireflective coating by Tanabe et al. [10]. In order to mitigate the gap between the theoretical and experimental results, researchers are constantly probing new approaches to heighten the efficiency of the IBSC devices. A major part of the ongoing research is devoted to increase the photocurrent generation of two-step photon absorption. However, limited attention has been paid to the structural issues such as the dot shape, size, dot-to-dot spacing, and number of IBs which have a 


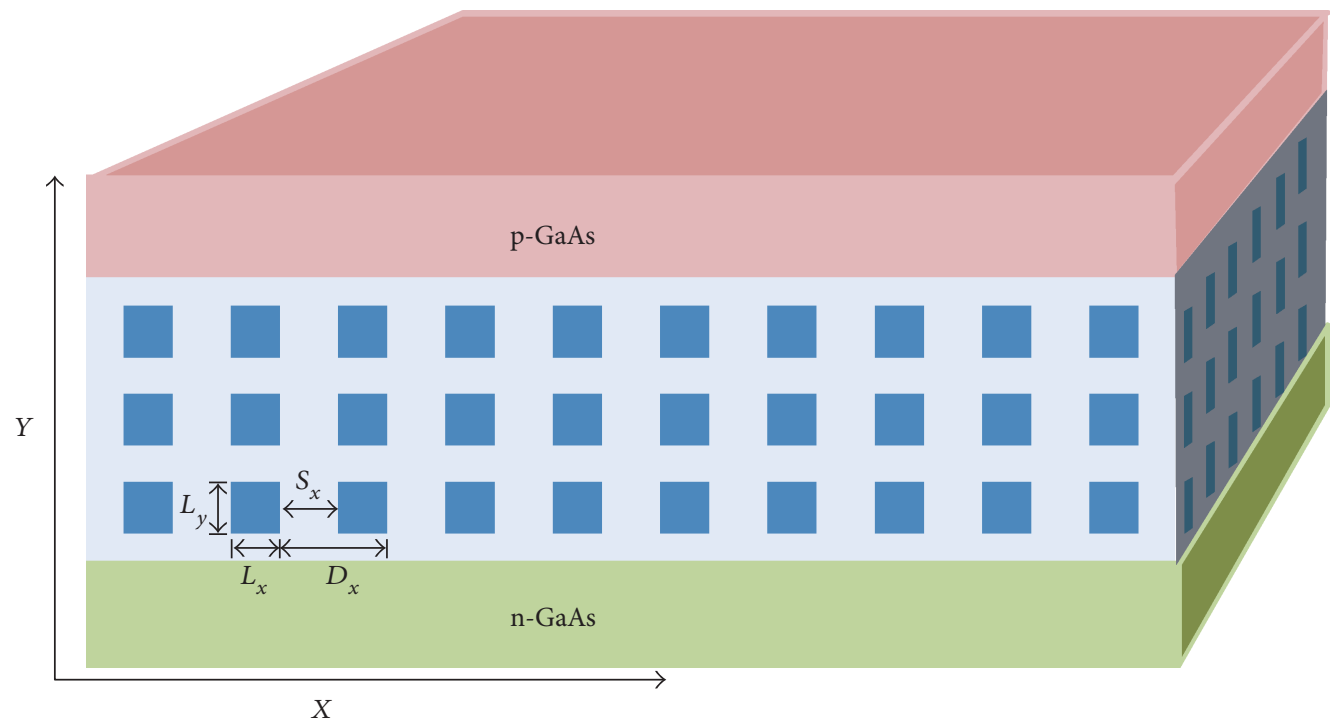

(a)

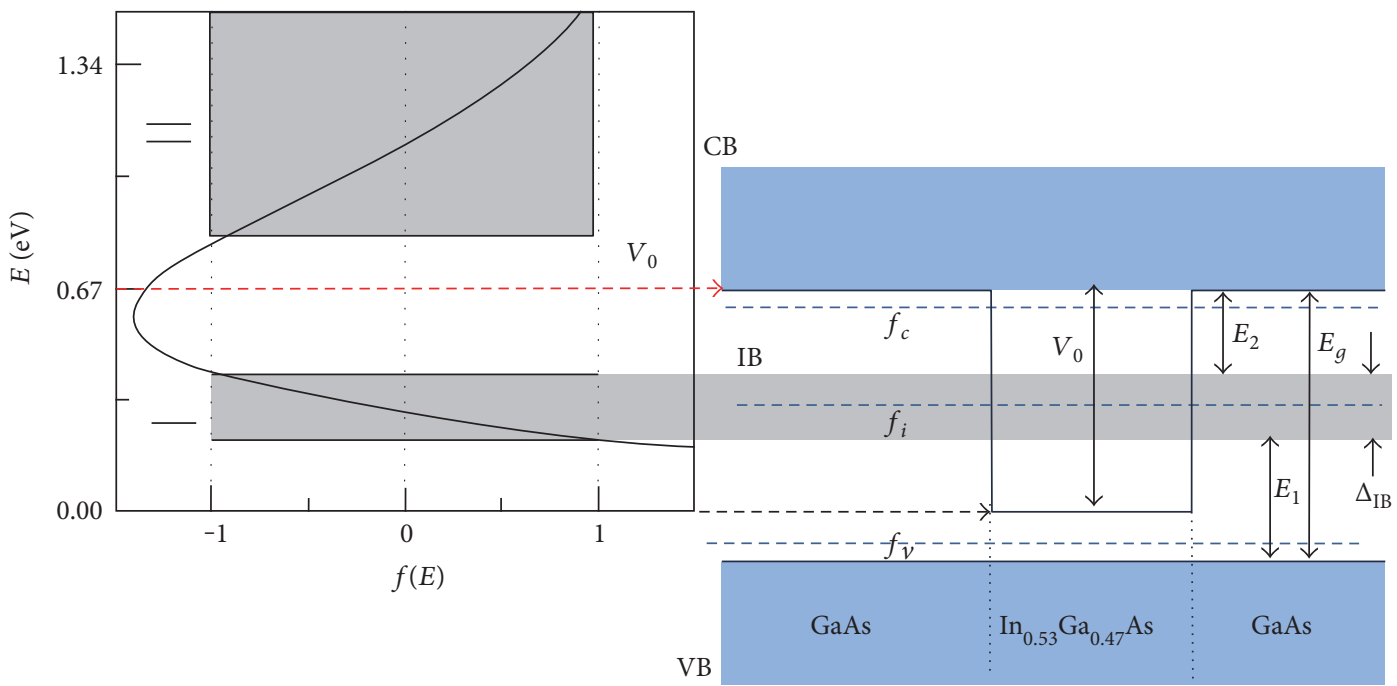

(b)

Figure 1: (a) Schematic structure and (b) miniband dispersion along with energy band diagram of $\operatorname{In}_{0.53} \mathrm{Ga}_{0.47} \mathrm{As} / \mathrm{GaAs}$ quantum dot intermediate band solar cell.

significant impact on the collection efficiency of photongenerated carriers. Advancement in the structural issues can pave the way for higher efficiency and eventually provide a guideline for growth engineers. In our previous study, we demonstrated the influence of $\operatorname{In}_{0.53} \mathrm{Ga}_{0.47} \mathrm{As} / \mathrm{GaAs}$ QDs in the IBSC and obtained the values of horizontal and vertical dot spacing which exhibited the maximum efficiency [11]. In this work, a detailed analysis of electron wave function for different dot spacing and size have been performed. The relation between the dot size and number of IBs is determined from the discrete quantized energy levels of quantum dots. Further, the characteristic parameters of the device, such as conversion efficiency, $\eta$, short circuit current density, $J_{\text {sc }}$, and open circuit voltage, $V_{\text {oc }}$, have been evaluated, and their relation with the widths and subbandgaps of the IB was derived.

\section{Theory and Model}

In the present work, a QDIBSC model consisting of $\mathrm{In}_{0.53} \mathrm{Ga}_{0.47} \mathrm{As}$ dots and GaAs barrier material is studied. The schematic structure of the device is shown in Figure 1(a). As the $\operatorname{In}_{0.53} \mathrm{Ga}_{0.47}$ As QDs are regularly placed in the intrinsic region of the p-i-n GaAs cell, the energy levels spread out into minibands. For the analysis, the $\operatorname{In}_{0.53} \mathrm{Ga}_{0.47} \mathrm{As}$ dots are assumed to have a cubical structure with equal dimensions, and the size of each dot in an infinite sequence is denoted by $L_{x}, L_{y}$, and $L_{z}$ along with the three coordinate axis directions as depicted in Figure 1(a). $S_{x}, S_{y}$, and $S_{z}$ stand for the interdot spacing/dot spacing along with the three coordinate axes. $D_{\xi}=L_{\xi}+S_{\xi}$ stands for a single period of QDs. Both the dot size and spacing are assumed to be equivalent along with every direction. The device is simulated using 
the commercial software Silvaco ATLAS [12]. All calculations are performed at a room temperature under AM 1.5, 1 sun condition. The values of the band parameters used in the simulation are presented in Table 1.

To describe the wave function of electrons in dot and barrier, the time-independent Schrodinger equation and Kronig-Penney model are used [13]. Figure 1(b) shows the energy band diagram along with the wave function of electron inside the $\mathrm{In}_{0.53} \mathrm{Ga}_{0.47}$ As dots and $\mathrm{GaAs}$ barrier. The structure produces two potential energies for the barrier, one for conduction band electrons, that is, conduction band offset, $V_{0}$, and the other for valence band holes, that is, valence band offset. For the simplicity of analysis, it is assumed that the energy corresponding to the top of the valence band is the same both in the barrier and in the dot; that is, the valence band offset is zero. As a consequence, only the effect of the conduction band offset, $V_{0}$, to create the wave vectors is considered. The effects of strain and piezoelectricity are ignored, and their effects on the electronic and optical properties of the QD array are also neglected. The Schrodinger equation in a quantum dot array for a single electron can be expressed as [13]

$$
\left[-\frac{\hbar^{2}}{2} \nabla_{r} \frac{1}{m^{*}(r)} \nabla_{r}+V(r)\right] \phi(r)=E \phi(r),
$$

where the electronic potential, $V(r)=V x(x)+V y(y)+V$ $z(z)$, is the sum of the potential functions $D_{x}, D_{y}$, and $D_{z}$ along with the three dimensional directions, respectively. In $\hbar=h / 2 \pi, h$ is Planck's constant and $\phi(r)$ is the envelope wave function. According to the Kronig-Penney model [13], the solution of the Schrodinger equation (1) can be given in the following form.

The energy of a single electron along a particular coordinate axis direction, $E_{\xi}$, is greater than or equal to the potential barrier, $V_{0}$, that is, if $E_{\xi} \geq V_{0}$,

$$
\begin{aligned}
\cos (q \xi D \xi)= & \cos \left(k_{\xi}^{w} L \xi\right) \cos \left(k_{\xi}^{B} S_{\xi}\right) \\
& -\frac{1}{2}\left(\frac{k_{\xi}^{w} m_{B}^{*}}{k_{\xi}^{B} m_{w}^{*}}+\frac{k_{\xi}^{B} m_{w}^{*}}{k_{\xi}^{w} m_{B}^{*}}\right) \sin \left(k_{\xi}^{w} L_{\xi}\right) \times \sin \left(k_{\xi}^{B} S_{\xi}\right) .
\end{aligned}
$$

$$
\begin{aligned}
& \text { If } 0<E_{\xi}<V_{0}, \\
& \begin{aligned}
\cos (q \xi D \xi)= & \cos \left(k_{\xi}^{w} L \xi\right) \cosh \left(k_{\xi}^{B} S_{\xi}\right) \\
& -\frac{1}{2}\left(\frac{k_{\xi}^{w} m_{B}^{*}}{k_{\xi}^{B} m_{w}^{*}}-\frac{k_{\xi}^{B} m_{w}^{*}}{k_{\xi}^{w} m_{B}^{*}}\right) \sin \left(k_{\xi}^{w} L_{\xi}\right) \times \sinh \left(k_{\xi}^{B} S_{\xi}\right),
\end{aligned}
\end{aligned}
$$

where

$$
\begin{aligned}
& k_{\xi}^{B}=\frac{\sqrt{2 m_{B}^{*}\left|E_{\xi}-V_{0}\right|}}{\hbar}, \\
& k_{\xi}^{w}=\frac{\sqrt{2 m_{w}^{*}\left|E_{\xi}\right|}}{\hbar},
\end{aligned}
$$

TABLE 1: Values of different parameters [15].

\begin{tabular}{lcc}
\hline \multirow{2}{*}{ Parameters } & \multicolumn{2}{c}{ Values } \\
& $\mathrm{GaAs}$ & $\mathrm{In}_{0.53} \mathrm{Ga}_{0.47} \mathrm{As}$ \\
\hline Bandgap $(\mathrm{eV})$ & 1.42 & 0.75 \\
Electron effective mass $\left(m_{0}\right)$ & 0.067 & 0.0452 \\
Permittivity $(\mathrm{F} / \mathrm{cm})$ & 13.2 & 14.2 \\
Electron affinity $(\mathrm{eV})$ & 4.07 & 4.13 \\
Density of states in & $4.35 \times 10^{17}$ & $1.15 \times 10^{17}$ \\
conduction band $\left(\mathrm{cm}^{-3}\right)$ & & \\
Density of states in & $8.16 \times 10^{18}$ & $8.12 \times 10^{18}$ \\
valence band $\left(\mathrm{cm}^{-3}\right)$ & & 1 \\
Electron/hole lifetime $(\mathrm{ns})$ & & \multicolumn{2}{c}{} \\
\hline
\end{tabular}

where $m_{B}^{*}$ and $m_{w}^{*}$ are the effective masses of electron in the barrier region and dot region, respectively. In order to obtain the electron wave vector in the dot and barrier regions, the left side of (2) and (3), $\cos (q \xi D \xi)$, can be expressed as a function $f\left(E_{\xi}\right)$ of energy $E_{\xi}[14]$.

For $E_{\xi} \geq V_{0}$,

$$
\begin{aligned}
f\left(E_{\xi}\right)= & \cos \left(k_{\xi}^{w} L \xi\right) \cos \left(k_{\xi}^{B} S_{\xi}\right) \\
& -\frac{1}{2}\left(\frac{k_{\xi}^{w} m_{B}^{*}}{k_{\xi}^{B} m_{w}^{*}}+\frac{k_{\xi}^{B} m_{w}^{*}}{k_{\xi}^{w} m_{B}^{*}}\right) \sin \left(k_{\xi}^{w} L_{\xi}\right) \times \sin \left(k_{\xi}^{B} S_{\xi}\right) .
\end{aligned}
$$

For $0<E_{\xi}<V_{0}$,

$$
\begin{aligned}
f\left(E_{\xi}\right)= & \cos \left(k_{\xi}^{w} L \xi\right) \cosh \left(k_{\xi}^{B} S_{\xi}\right) \\
& -\frac{1}{2}\left(\frac{k_{\xi}^{w} m_{B}^{*}}{k_{\xi}^{B} m_{w}^{*}}-\frac{k_{\xi}^{B} m_{w}^{*}}{k_{\xi}^{w} m_{B}^{*}}\right) \sin \left(k_{\xi}^{w} L_{\xi}\right) \times \sinh \left(k_{\xi}^{B} S_{\xi}\right) .
\end{aligned}
$$

Apparently, from (5) and (6), the left hand side is a function of energy $(E)$ only which should be constrained by \pm 1 [13]. As the energy changes from 0 to $V_{0},(5)$ and (6) determine the IBs inside the potential barrier, $V_{0}$. For $\mathrm{In}_{0.53} \mathrm{Ga}_{0.47} \mathrm{As}$ dots, Figure 1(b) exhibits two minibands labeled as miniband I $(0.087,0.235)$ and miniband II $(0.424,0.938)$. As the valence band offset is assumed to be zero, the value of potential barrier $V_{0}$ can be calculated by subtracting the bandgap of the dot from the barrier material. For $\operatorname{In}_{0.53} \mathrm{Ga}_{0.47}$ As dots, the value of $V_{0}$ is found to be $0.67 \mathrm{eV}$. As seen from Figure 1(b), the miniband I has energy lower than $V_{0}$; subsequently, it is located inside the dot, whereas miniband II has energy above $V_{0}$, hence distributed in the barrier region. As the minibands in the barrier become a part of the conduction band, only the minibands formed inside the dots are regarded as IBs. For the separation of minibands from the $\mathrm{CB}$ and $\mathrm{VB}$, it is crucial to determine their widths. The widths of the formed minibands can be calculated from Figure 1(b). The total width of the miniband I is equal to 3 times the width of miniband I along with every direction. So, $\Delta_{\mathrm{IB}}=3 \times($ the bottom point of miniband I-starting point of miniband $\mathrm{I})=3 \times(0.235-0.087) \mathrm{eV}=0.444 \mathrm{eV}$. 


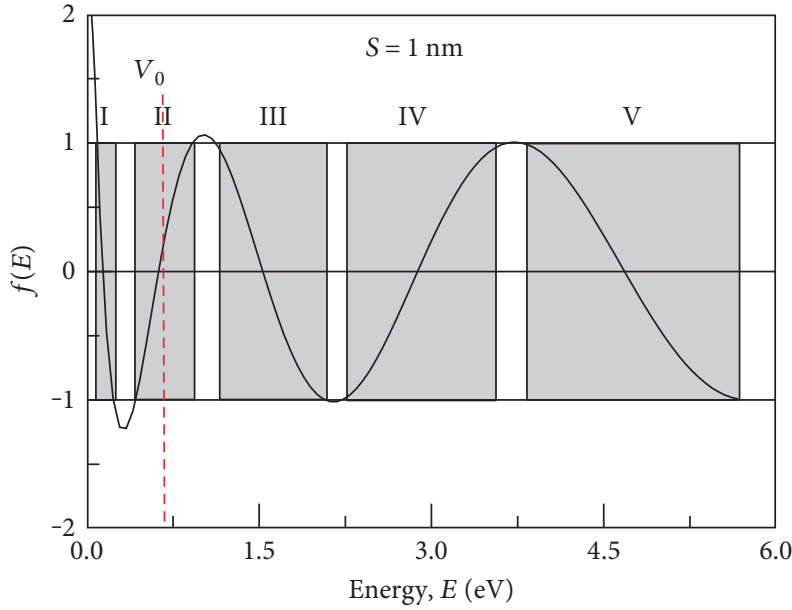

(a)

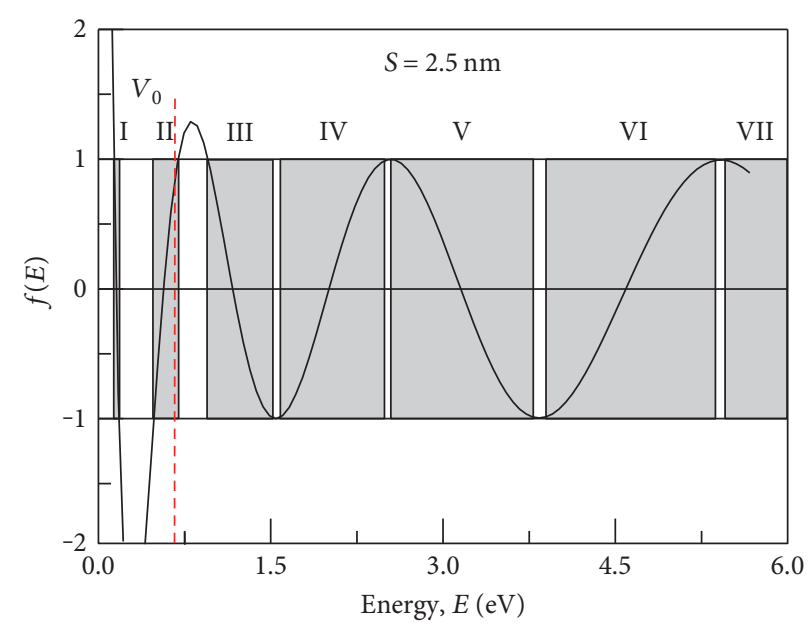

(b)

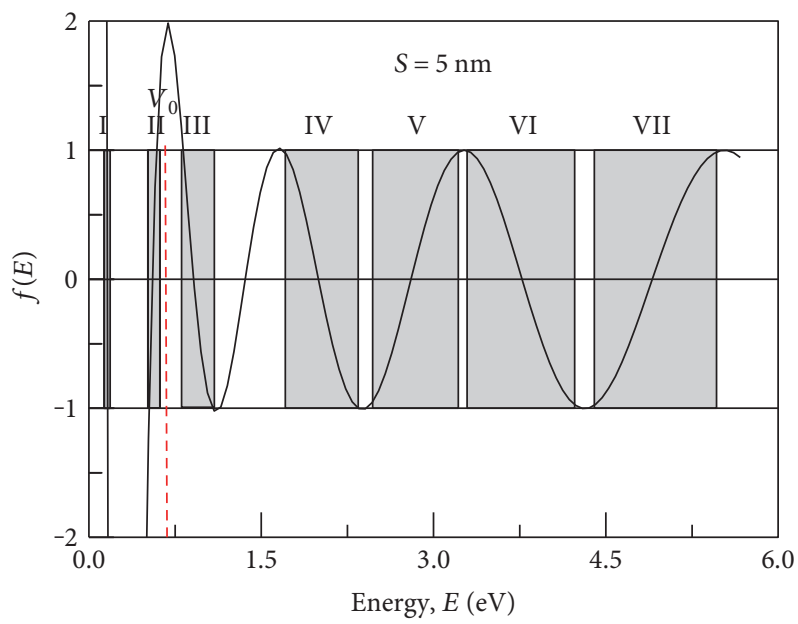

(c)

FIgURE 2: Miniband dispersion in $\operatorname{In}_{0.53} \mathrm{Ga}_{0.47}$ As QDIBSC for dot spacing of (a) $1 \mathrm{~nm}$, (b) $2.5 \mathrm{~nm}$, and (c) $5 \mathrm{~nm}$.

The subbandgap, $E_{1}$, can be given by $E_{1}=\mathrm{E}_{\mathrm{gIn} 0.53 \mathrm{Ga} 0.47 \mathrm{As}}+$ $3 \times$ (starting point of miniband I) $\mathrm{eV}=\mathrm{E}_{\mathrm{gIn} 0.53 \mathrm{Ga0} .47 \mathrm{As}}{ }^{+}$ $3 \times(0.087) \mathrm{eV}$ where $\mathrm{E}_{\mathrm{gIn} 0.53 \mathrm{Ga0} .47 \mathrm{As}}$ is the bandgap of $\mathrm{In}_{0.53} \mathrm{Ga}_{0.47} \mathrm{As}$. The subbandgap $E_{2}$ is given by $E_{2}=E_{\mathrm{g}}-$ $E_{1}-\Delta_{\mathrm{IB}} \mathrm{eV}$ for a single IB.

\section{Results and Discussion}

3.1. Dot Spacing. In our previous study, we found the values of dot spacing which yielded the maximum efficiency for $\mathrm{In}_{0.53} \mathrm{Ga}_{0.47} \mathrm{As} / \mathrm{GaAs}$ QDIBSC [11]. However, relation between the dot spacing and the distribution of IB energies in the forbidden gap was not studied. Here, we commence the discussion first by manifesting the relation of dot spacing, $S$, with the electron wave function and then with the width and position of IB. The bandwidth $f(E)$, as a function of different dot spacing $(S=1 \mathrm{~nm}, 2.5 \mathrm{~nm}$, and $5 \mathrm{~nm})$ for a fixed value of dot size $(L=5 \mathrm{~nm})$, in the dot and barrier regions is depicted in Figure 2. From Figure 2, it is recognized that in all three cases, that is, Figures 2(a), 2(b), and 2(c) miniband I lies inside the boundary of $V_{0}$, while miniband II remains outside. As a consequence, miniband $\mathrm{I}$ is the only intermediate band found in the forbidden energy gap. It is also seen that the distance between miniband I and $\mathrm{CB}$ increases with increasing $S$ from $1 \mathrm{~nm}$ to $5 \mathrm{~nm}$, producing more number of minibands. Figure 3 demonstrates the variation of the width of the miniband I, $\Delta_{\mathrm{IB}}$, with dot spacing, $S$, and the subbandgaps, $E_{1}$ and $E_{2}$.Inside the host gap, the subbandgaps $E_{1}$ and $E_{2}$ determine the position of the IB. Figure 3 shows increasing $S$ evidently broadens the subbandgaps $E_{1}$ and $E_{2}$ shrinking the width $\Delta_{\mathrm{IB}}$ to a value close to zero. As shown in Figure 3(a), from $1 \mathrm{~nm}$ to $2.5 \mathrm{~nm}$, the value of $\Delta_{\mathrm{IB}}$ decreases from $0.444 \mathrm{eV}$ to $0.135 \mathrm{eV}$, while from $2.5 \mathrm{~nm}$ to $5 \mathrm{~nm}$, it decreases to $0.018 \mathrm{eV}$. The reduction in $\Delta_{\text {IB }}$ can be assigned to the decrease in the quantum states and the weak coupling of wave functions in more distant dots. In Figure 3(b), from $1 \mathrm{~nm}$ to $2.5 \mathrm{~nm}$, both $E_{1}$ and $E_{2}$ increase approximately $13.6 \%$, which can be attributed to the enhancement of quantum localization. These results also coincide with other works which exhibit that increasing the dot spacing results in reduced IB widths [16]. However, a larger value of $\Delta_{\mathrm{IB}}$ is beneficial for the absorption of more sunlight to increase the current, whereas diminishing $E_{1}$ and $E_{2}$ will reduce it. As a consequence, it is in this regard 


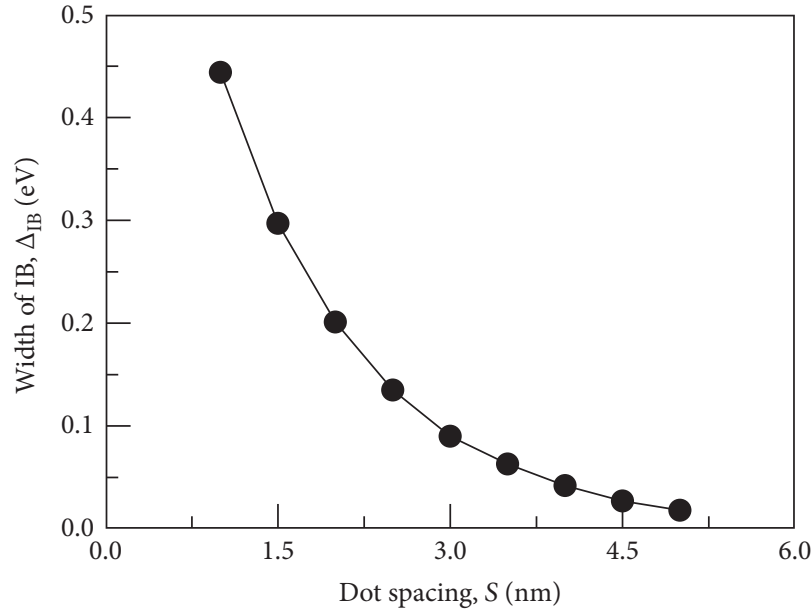

(a)

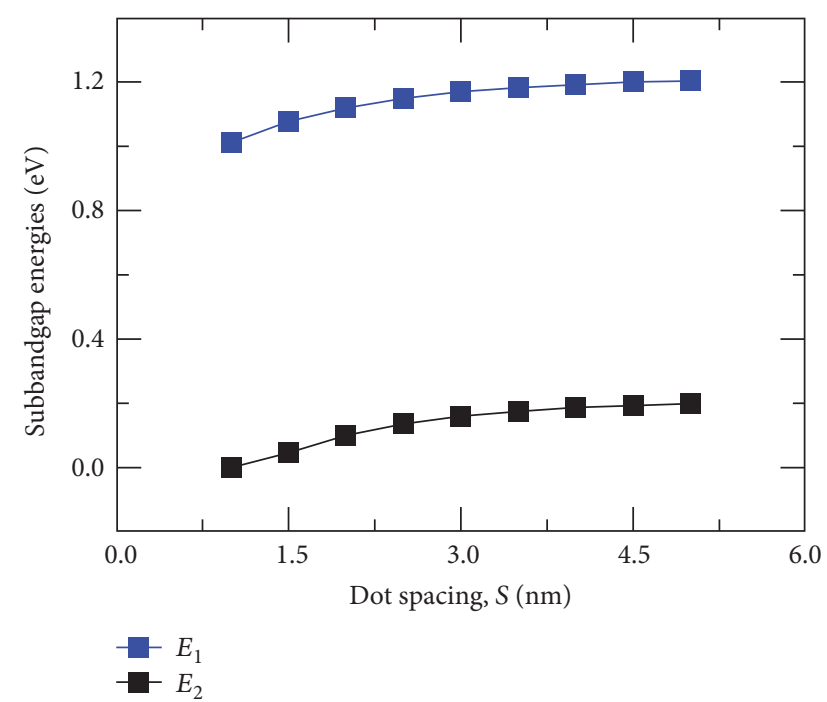

(b)

FIgURE 3: Variation of (a) IB width $\Delta_{\mathrm{IB}}$ and (b) subbandgaps $E_{1}$ and $E_{2}$ with dot spacing, $S$, for a single IB.

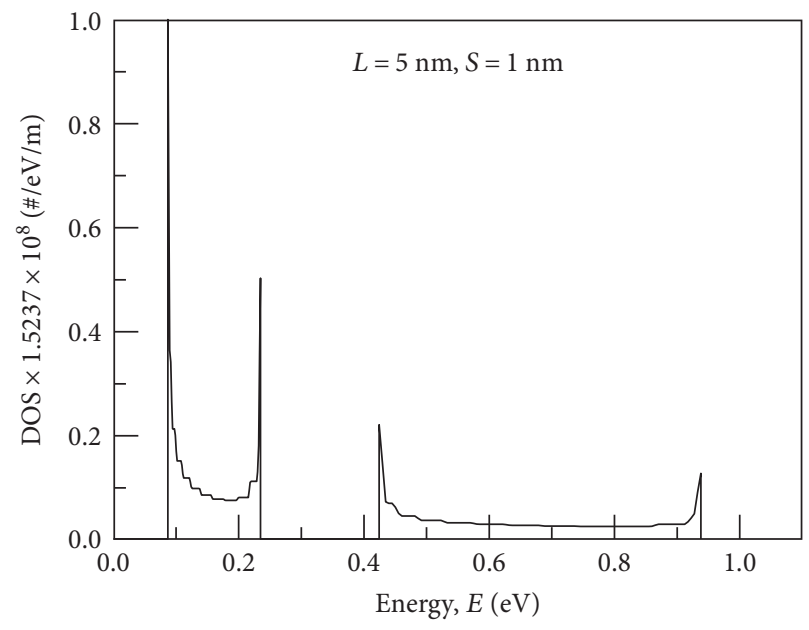

(a)

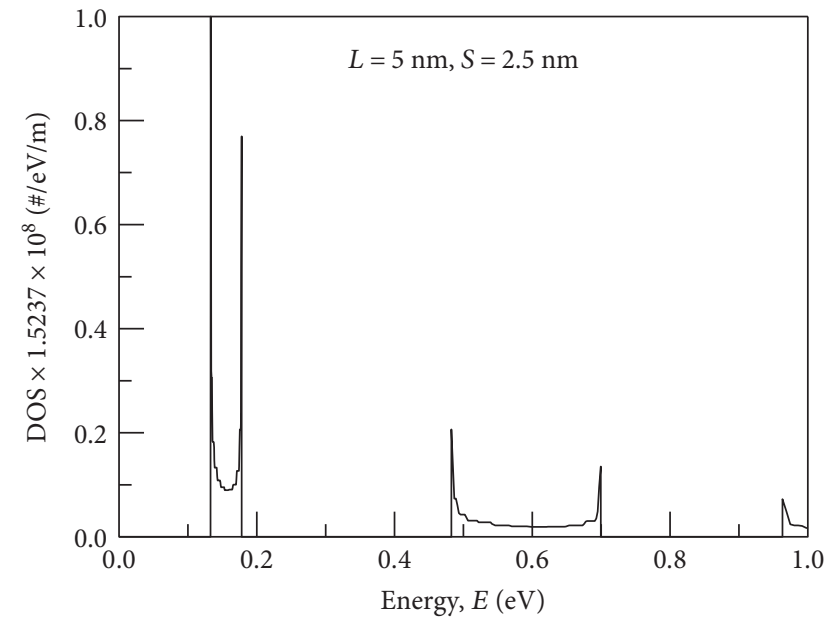

(b)

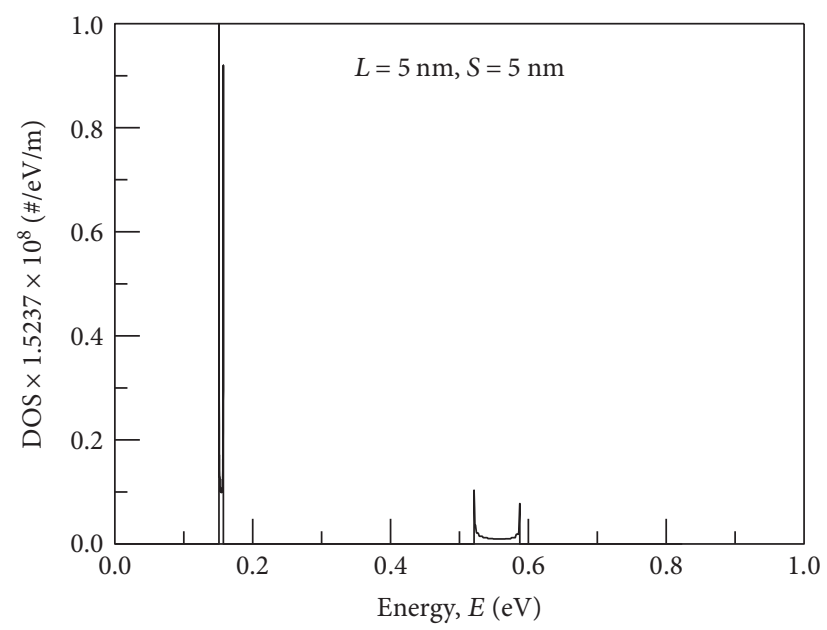

(c)

Figure 4: The electron density of states (DOS) in the minibands for dot spacing of (a) $1 \mathrm{~nm}$, (b) $2.5 \mathrm{~nm}$, and (c) $5 \mathrm{~nm}$. 


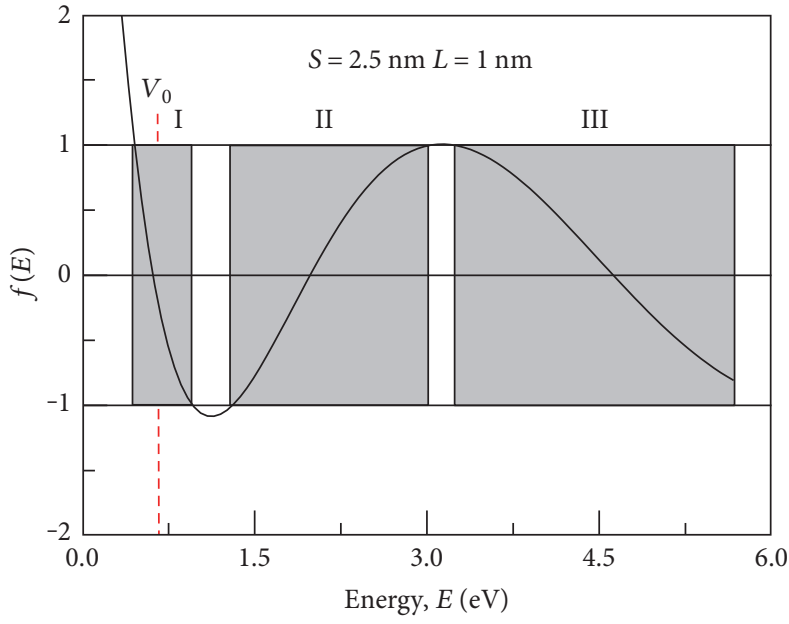

(a)

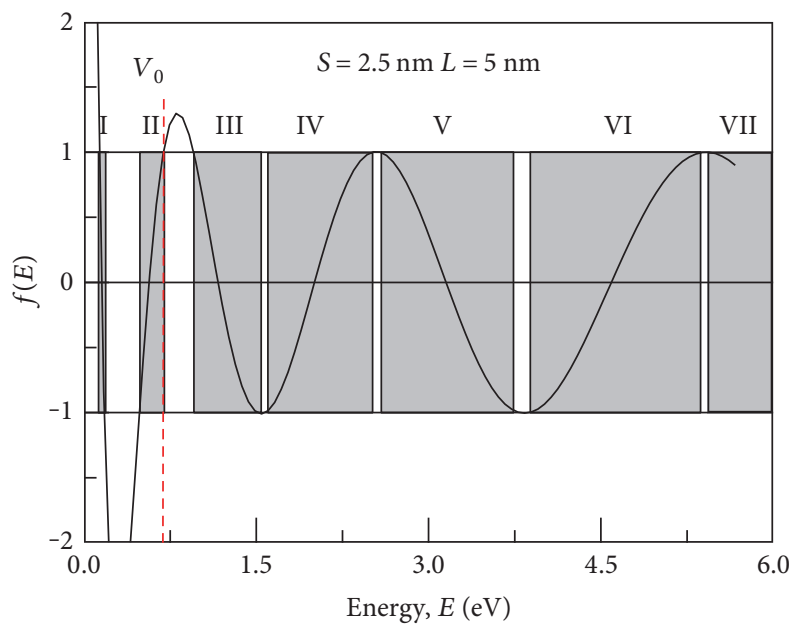

(c)

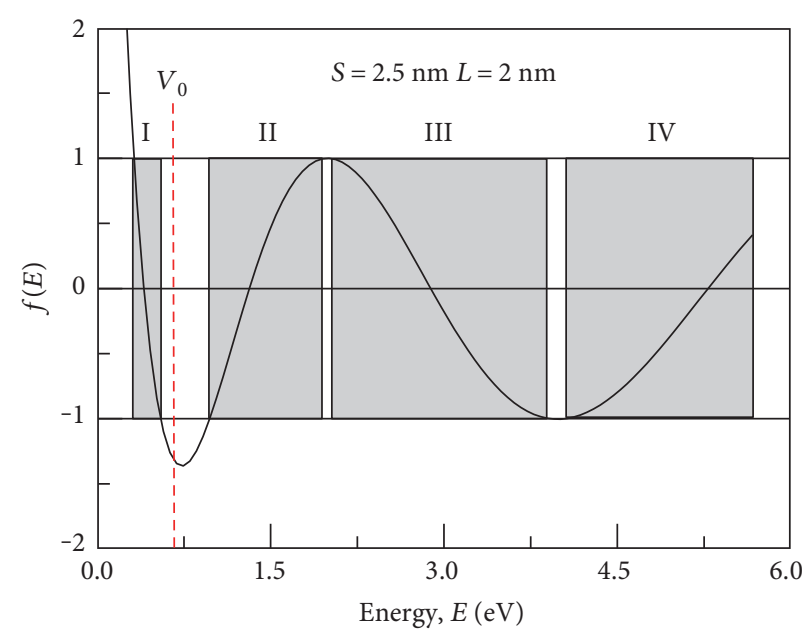

(b)

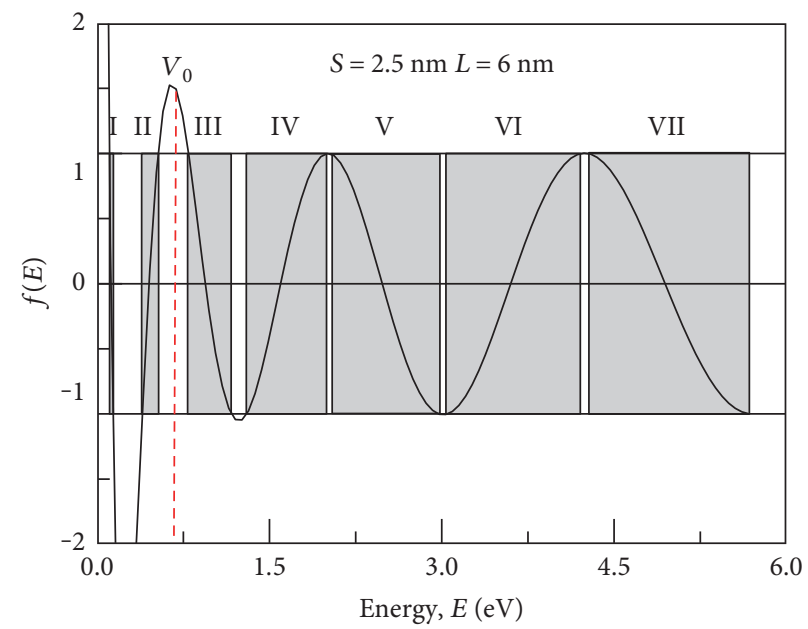

(d)

FIgure 5: Miniband dispersion in $\operatorname{In}_{0.53} \mathrm{Ga}_{0.47}$ As QDIBSC dot for different dot sizes of (a) $1 \mathrm{~nm}$, (b) $2 \mathrm{~nm}$, (c) $5 \mathrm{~nm}$, and (d) $6 \mathrm{~nm}$.

imperative to attain a trade-off between the higher values of $E_{1}$ and $E_{2}$ and the lower values of $\Delta_{\mathrm{IB}}$. Furthermore, the electron density of states (DOS) in IB has to be as high as possible in order to pin the quasi Fermi level at its equilibrium position [17]. The DOS in the minibands for $S=1 \mathrm{~nm}$, $2.5 \mathrm{~nm}$, and $5 \mathrm{~nm}$ is illustrated in Figure 4. As seen from Figure 4(a), for $S=1 \mathrm{~nm}$, a broad bandwidth of IB yields a high DOS, whereas for $S=5 \mathrm{~nm}$, a narrow IB assists in the loss of carrier density, that is, a lower DOS. It is therefore of great necessity to choose a value between $1 \mathrm{~nm}$ and $5 \mathrm{~nm}$ in order to obtain a sufficiently high IB width and subbandgaps. At $S=2.5 \mathrm{~nm}$, a moderate value of $\Delta_{\mathrm{IB}}$ and $E_{1}, E_{2}$ is achieved.

3.2. Dot Size. Next, the size of dots, $L$, is varied to infer its relation with the formed intermediate bands. $f(E)$ as a function of electron's energy is exhibited in Figure 5. Figures 5(a) and 5(b) illustrate the wave function of electron in the dot for $L=1 \mathrm{~nm}$ and $2 \mathrm{~nm}$. For $L=1 \mathrm{~nm}$, no intermediate band is formed as the miniband I extends to a value beyond the energy level of $V_{0}$. For $L=2 \mathrm{~nm}$, in Figure 5(b),
TABLE 2: Ranges of dot size which vary the number of IBs.

\begin{tabular}{lcc}
\hline & 1st range & 2nd range \\
\hline Size of dots & $2 \mathrm{~nm}-5 \mathrm{~nm}$ & $6 \mathrm{~nm}-9 \mathrm{~nm}$ \\
Number of IBs & $1 \mathrm{IB}$ & 2 IBs \\
\hline
\end{tabular}

miniband $I$ is regarded as an $I B$, as it remains inside the boundary value of $V_{0}$. This implies that, for $S=2.5 \mathrm{~nm}$, a dot size less than $2 \mathrm{~nm}$ does not form any intermediate band. From Figures 5(b), 5(c), and 5(d), it can be seen that, with subsequent increase in $L$ from $2 \mathrm{~nm}$, the number of minibands tend to increase. Up to $L=5 \mathrm{~nm}$, only miniband $\mathrm{I}$ is regarded as an IB (Figure 5(c)), whereas for $L=6 \mathrm{~nm}$ (Figure 5(d)), both miniband I and II are considered as IBs, as both have energies lower than $V_{0}$.

Hence, an apparent deduction that can be made from the miniband dispersion of Figure 5 is for a fixed spacing of $2.5 \mathrm{~nm}$; dot sizes ranging from $2 \mathrm{~nm}$ to $5 \mathrm{~nm}$ generate a single intermediate band whereas the dot sizes from $6 \mathrm{~nm}$ to $9 \mathrm{~nm}$ are more likely to produce two IBs. It also denotes that the 


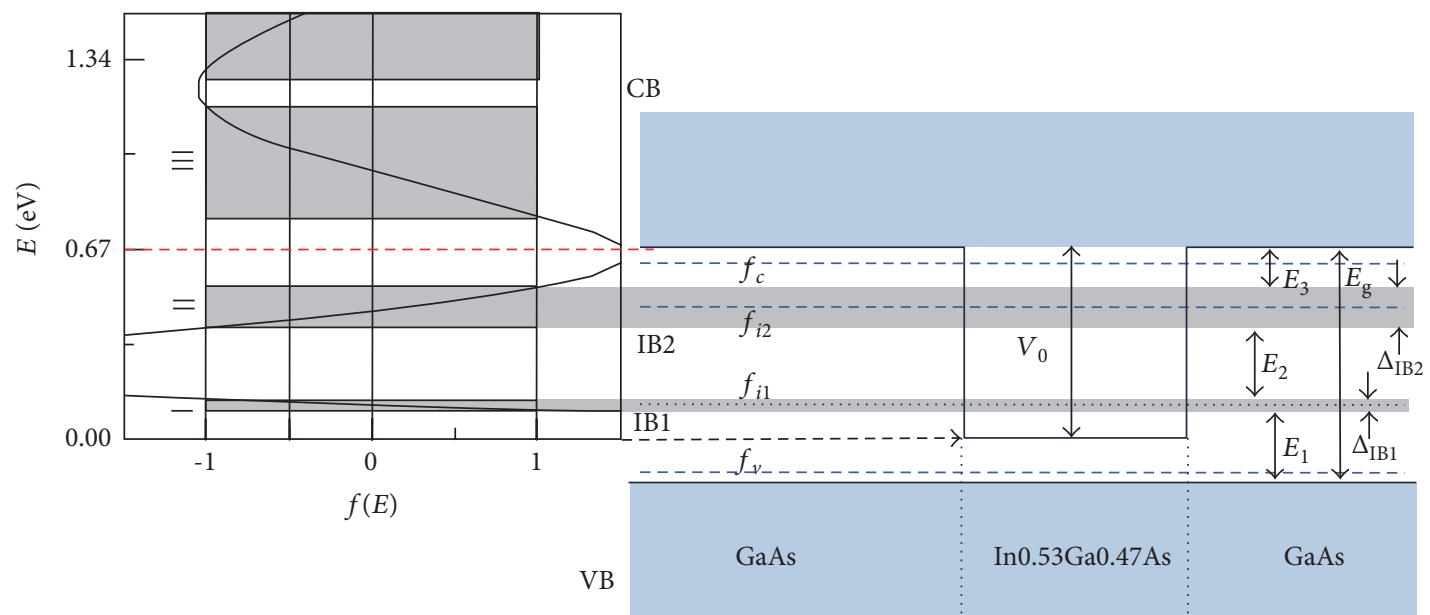

FIgURE 6: Energy band diagram and miniband dispersion of $\operatorname{In}_{0.53} \mathrm{Ga}_{0.47} \mathrm{As} / \mathrm{GaAs}$ quantum dot intermediate band solar cell for two intermediate bands.

number of IBs in a QD system is directly related to the size of dots. From these results, two ranges of dot sizes for a fixed dot spacing can be provided which vary the number of IBs. Table 2 shows these two ranges of dot sizes. The first range is from $L=2 \mathrm{~nm}$ to $5 \mathrm{~nm}$, under which a single intermediate band is attained. The second range is from $6 \mathrm{~nm}$ to $9 \mathrm{~nm}$, under which two intermediate bands are obtained. Figure 6 shows the energy band diagram and the distribution of minibands in dot and barrier for two IBs.

The width of the first intermediate band $\Delta_{\mathrm{IB} 1}$ as a function of dot size is shown in Figure 7(a). As the size of the dot increases from $2 \mathrm{~nm}$ to $5 \mathrm{~nm}$, the width tends to decrease. The same trend is also found in Figure $7(\mathrm{~b})$, where the widths, $\Delta_{\mathrm{IB} 1}$ and $\Delta_{\mathrm{IB} 2}$, decrease with rising $L$. This decrease can be assigned to the fact that the overlap quantized levels between different QDs become small, which can cause a decline in the transitional probabilities of photo-generated carriers from VB to CB via IBs. Also, the quantum effect on the low-quantized levels is stronger than that on the higher ones. A high value of $\Delta_{\text {Ів2 }}$ is essential to include most of the excited electrons that come from the lower subband $\Delta_{\mathrm{IB} 1}$ and $\mathrm{VB}$, respectively.

Compared to a single IB, two IBs in a QDIBSC have six upward transitions and three subbandgaps $E_{1}, E_{2}$, and $E_{3}$ as shown in Figure 6. Introducing more levels in the bandgap increases the number of upward transitions as well as the probability of absorption of low-energy photons. According to the bound state energy levels obtained for typical QD parameters, the subbandgap energies are organized as $E_{1}>E_{2}>E_{3}$. This condition is important as it preserves the discrete nature of QDs inside the host semiconductor material. Figure 7(c) illustrates the variation of the subbandgaps $E_{1}, E_{2}$, and $E_{3}$ with the second range of dot sizes for two IBs. In Figure $7(c)$, subbandgaps $E_{1}$ and $E_{2}$ descend with the increasing $L$ while $E_{3}$ shows an ascending trend. The increase in $L$ tends to decrease the gap between $\mathrm{VB}$ and $\Delta_{\mathrm{IB} 1}$ and also the gap between $\Delta_{\mathrm{IB} 1}$ and $\Delta_{\mathrm{IB} 2}$. However, at the same time, an increasing $L$ leads to an increase in the gap between $\mathrm{CB}$ and $\Delta_{\mathrm{IB} 2}$ due to a fixed host gap of GaAs. Since the positions of the two intermediate bands are determined by the subbandgaps $E_{1}, E_{2}$, and $E_{3}$, an optimization of these subbandgaps is required for achieving the maximum cell efficiency.

The variation of the current density, $J_{\mathrm{sc}}$, and open circuit voltage, $V_{\mathrm{oc}}$, with two ranges of $L$ is illustrated in Figure 8 . From $2 \mathrm{~nm}$ to $5 \mathrm{~nm}$, the $J_{\mathrm{sc}}$ increases around $6.5 \%$ while the open circuit voltage $V_{\mathrm{oc}}$ remains almost constant. The enhancement in the current density with dot size can be attributed to the increase in a generation rate. Larger dots lead to higher generation rates [18] and broaden the range of photon energy which can further result in creation of electron-hole pairs that in turn boosts the $J_{\mathrm{sc}}$. On the other hand, as the $V_{\mathrm{oc}}$ is dependent on the chemical potential between $\mathrm{VB}$ and $\mathrm{CB}$, in other words, in the host bandgap, $E_{g}$, the variation in $L$ does not affect $E_{g}$; hence, $V_{\text {oc }}$ implies a weak dependence on $L$. In the second range of $L$, from $6 \mathrm{~nm}$ to $7 \mathrm{~nm}, J_{\mathrm{sc}}$ increases around $1 \%$ and then decreases. This slight increase in the current can be assigned to the formation of a second IB which heightens the photo collection efficiency. Beyond $L=$ $7 \mathrm{~nm}$, the decreasing slope of $J_{\mathrm{sc}}$ can be due to the positioning of the two IBs in the host gap. The peak value of $J_{s c}$ is achieved at $L=5 \mathrm{~nm}$ and $L=7 \mathrm{~nm}$ for $1 \mathrm{IB}$ and 2 IBs, respectively. Figure 9 shows the $J-V$ characteristic curves for single IB and two IBs for optimized $L$ values. For a single IB, the maximal efficiency of $22.8 \%$ is achieved at $L=5 \mathrm{~nm}$ due to the obtained maximum $J_{\mathrm{sc}}$. For two IBs, the optimal efficiency is around $22.6 \%$ for $L=7 \mathrm{~nm}$. Table 3 shows the summarized results of $J_{\mathrm{sc}}, V_{\mathrm{oc}}, F F$, and $\eta$ for no IB, that is, a single junction GaAs cell, 1 IB, and 2 IBs. From Table 3, it is found that, without the insertion of QD layer, the efficiency of the cell is $21.5 \%$ which increases approximately $6.04 \%$ and $5.1 \%$ with inclusion of $1 \mathrm{IB}$ and 2 IBs, respectively. The insertion of QD layers introduces several confined electrons and hole states inside the intrinsic region which enhance the drifting action of the carriers by making use of the built-in electric field of the $p-n$ junction. Increasing the number of IBs in a QDIBSC should lead to higher efficiency. Theoretically, two IBs should have higher efficiency compared to 1 IB. However, for $\operatorname{In}_{0.53} \mathrm{Ga}_{0.47} \mathrm{As} / \mathrm{GaAs}$, it is found that two IBs resulted in a lower efficiency than that of using one IB, 


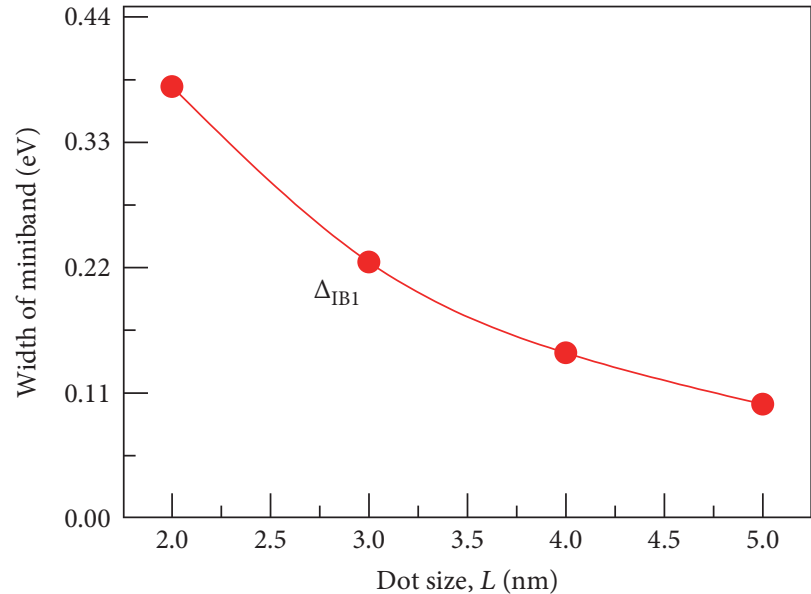

(a)

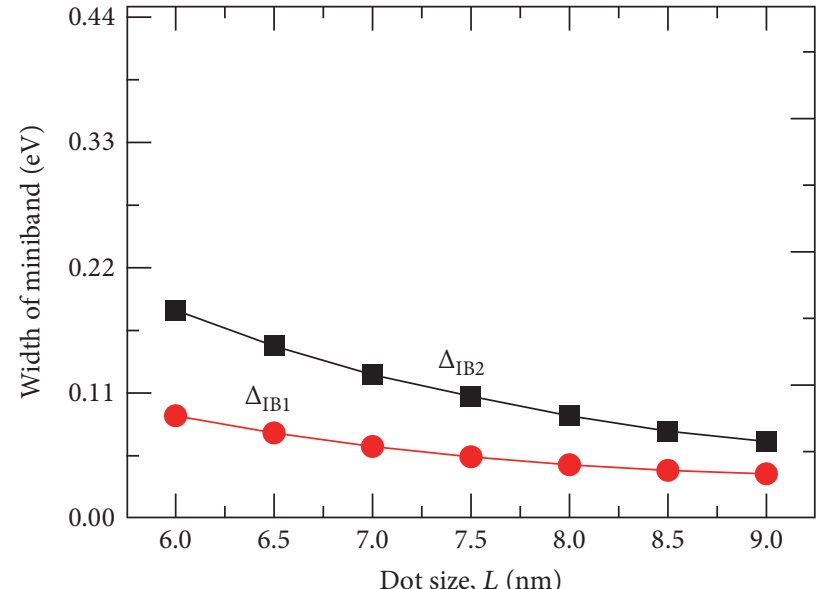

(b)

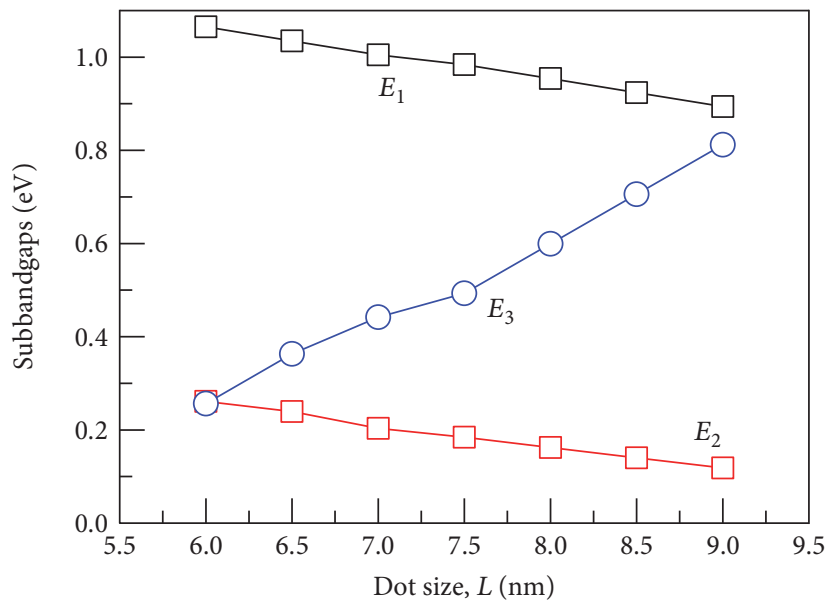

(c)

FIGURE 7: (a) Variation of $\Delta_{\mathrm{IB} 1}$ with the 1st range of dot size. (b) Variations of $\Delta_{\mathrm{IB} 1}$ and $\Delta_{\mathrm{IB} 2}$ with the second range of dot size and (c) subbandgaps $E_{1}, E_{2}$, and $E_{3}$ with dot size.

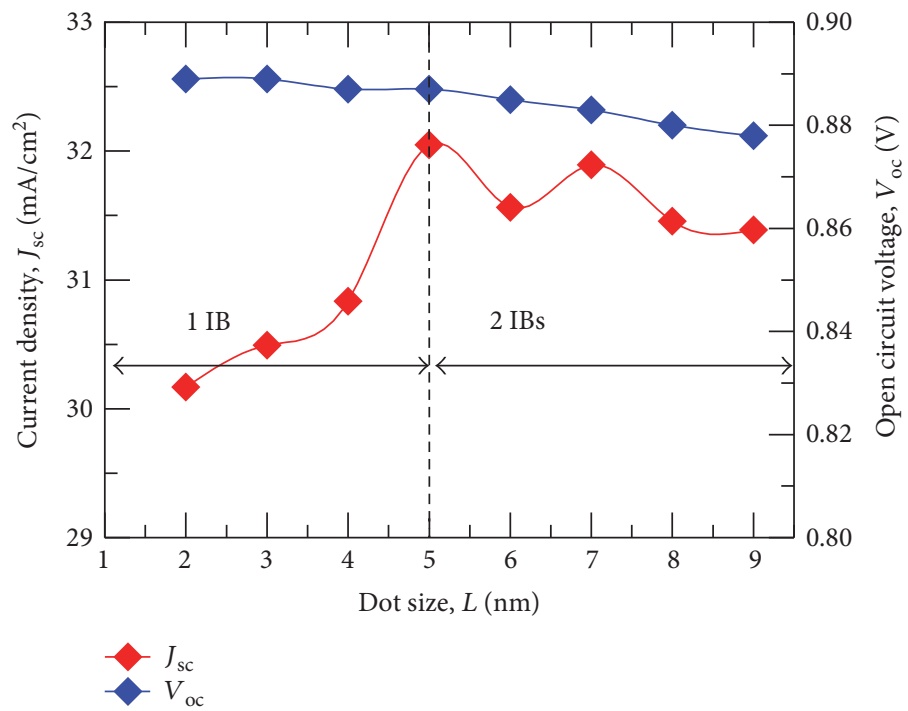

Figure 8: Dot size versus $J_{\mathrm{sc}}$ and $V_{\mathrm{oc}}$ for $1 \mathrm{IB}$ and 2 IBs. 


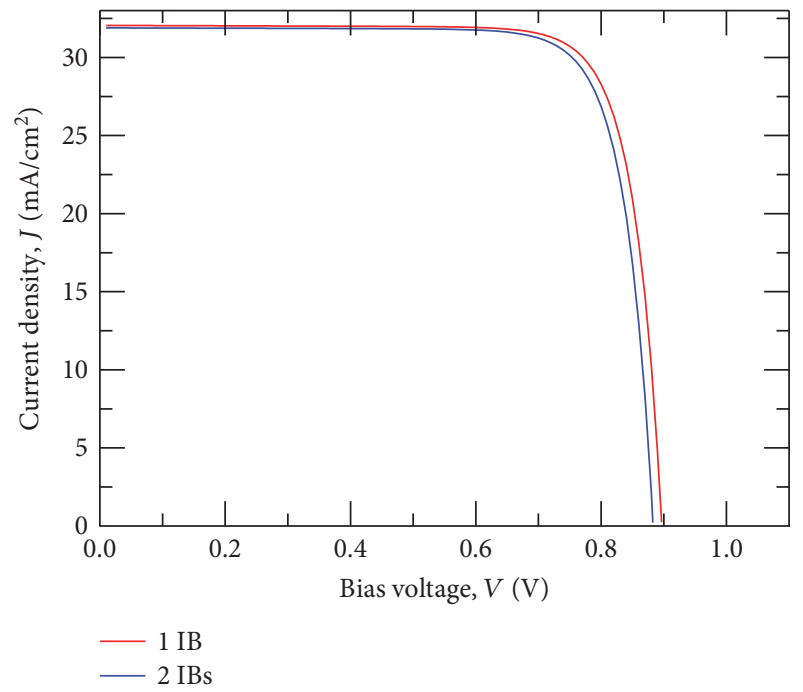

FIgURE 9: $J-V$ characteristic curves for $1 \mathrm{IB}$ and 2 IBs.

TABle 3: Summarized results of $J_{\mathrm{sc}}, V_{\mathrm{oc}}, F F$, and $\eta$ for 0,1 , and 2 intermediate bands.

\begin{tabular}{lcccc}
\hline Number of IBs & $J_{\mathrm{sc}}\left(\mathrm{mA} / \mathrm{cm}^{2}\right)$ & $V_{\mathrm{oc}}($ volt $)$ & $F F(\%)$ & $\eta(\%)$ \\
\hline 0 & 29.5 & 0.9 & 81.2 & 21.5 \\
1 IB & 32.05 & 0.886 & 80.3 & 22.8 \\
2 IBs & 31.89 & 0.883 & 80.3 & 22.6 \\
\hline
\end{tabular}

by a margin of $0.2 \%$. This decrease could have been caused due to a narrow host gap, $E_{g}$ (for $\operatorname{In}_{0.53} \mathrm{Ga}_{0.47} \mathrm{As}, E_{g}$ is fixed at a value of $1.42 \mathrm{eV}$ ). For two IBs to surpass one IB in efficiency, the host gap should have a value greater than or equal to $2 \mathrm{eV} \mathrm{[19].} \mathrm{Efficiency} \mathrm{of} \mathrm{two} \mathrm{IBs} \mathrm{is} \mathrm{likely} \mathrm{to} \mathrm{exceed} \mathrm{that} \mathrm{of}$ one $\mathrm{IB}$, given that there is a scope for independent energy transitions, that is, $E_{1}, E_{2}$, and $E_{g}$, to be optimized and matched well with the absorption of solar spectrum.

\section{Conclusion}

In this work, a study based on $\operatorname{In}_{0.53} \mathrm{Ga}_{0.47}$ As/GaAs QD array was investigated. Formation of minibands with regard to the behavior of electron wave function in dot and barrier regions for various dot spacing and sizes is analyzed. Results reveal that emergence of a second IB in $\mathrm{In}_{0.53} \mathrm{Ga}_{0.47}$ As/GaAs QDIBSC relies more on the size of dots than dot spacing. Increasing dot spacing results in a narrower IB width and a lower density of states, while increasing the dot size results in formation of multiple IBs. Based on the results obtained, two different ranges of dot sizes are provided which vary the number of IBs. Smaller dots ranging from the size of $2 \mathrm{~nm}$ to $5 \mathrm{~nm}$ yield a single IB while larger dots ranging from the size of $6 \mathrm{~nm}$ to $9 \mathrm{~nm}$ produce two IBs. The conversion efficiency of 2 IBs close to the efficiency of 1 IB suggests that multiple IBs can potentially improve the efficiency, if the host bandgap and subbandgaps are optimized to match well with the absorption of solar spectrum.

\section{Conflicts of Interest}

The authors declare that they have no conflicts of interest.

\section{References}

[1] A. Luque and A. Martí, "Increasing the efficiency of ideal solar cells by photon induced transitions at intermediate levels," Physical Review Letters, vol. 78, no. 26, pp. 5014-5017, 1997.

[2] W. Shockley and H. Queisser, "Detailed balance limit of efficiency of p-n junction solar cells," Journal of Applied Physics, vol. 32, no. 3, p. 510, 1961.

[3] A. Luque, A. Martí, and A. Nozik, "Solar cells based on quantum dots: multiple exciton generation and intermediate bands," MRS Bulletin, vol. 32, no. 03, pp. 236-241, 2007.

[4] A. Luque, A. Martí, and C. Stanley, "Understanding intermediate-band solar cells," Nature Photonics, vol. 6, no. 3, pp. 146-152, 2012.

[5] V. Aroutiounian, S. Petrosyan, A. Khachatryan, and K. Touryan, "Quantum dot solar cells," Journal of Applied Physics, vol. 89, no. 4, pp. 2268-2271, 2001.

[6] R. Strandberg and T. Reenaas, "Photofilling of intermediate bands," Journal of Applied Physics, vol. 105, no. 12, article 124512, 2009.

[7] Y. Okada, N. Ekins-Daukes, T. Kita et al., "Intermediate band solar cells: recent progress and future directions," Applied Physics Reviews, vol. 2, no. 2, article 021302, 2015.

[8] T. Li and M. Dagenais, "High saturation intensity in InAs/GaAs quantum dot solar cells and impact on the realization of the intermediate band concept at room-temperature," Applied Physics Letters, vol. 110, no. 6, article 061107, 2017.

[9] M. Green, Y. Hishikawa, W. Warta et al., "Solar cell efficiency tables (version 50)," Progress in Photovoltaics: Research and Applications, vol. 25, no. 7, pp. 668-676, 2017.

[10] K. Tanabe, D. Guimard, D. Bordel, and Y. Arakawa, "Highefficiency InAs/GaAs quantum dot solar cells by metalorganic chemical vapor deposition," Applied Physics Letters, vol. 100, no. 19, article 193905, 2012.

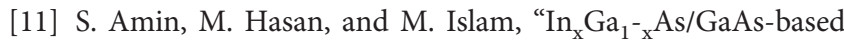
intermediate band solar cell: effects of quantum dots," in 2016 IEEE Region 10 Conference (TENCON), pp. 2753-2756, Singapore, 2016.

[12] Silvaco Support - Download User Manuals, "Dynamic.silvaco. com," 2017, https://dynamic.silvaco.com/dynamicweb/jsp/ downloads/DownloadManualsAction.do?req=silen-manuals\& $\mathrm{nm}=$ atlas.

[13] O. Lazarenkova and A. Balandin, "Miniband formation in a quantum dot crystal," Journal of Applied Physics, vol. 89, no. 10 , pp. 5509-5515, 2001.

[14] G. Bastard, "Theoretical investigations of superlattice band structure in the envelope-function approximation," Physical Review B, vol. 25, no. 12, pp. 7584-7597, 1982.

[15] I. Vurgaftman, J. Meyer, and L. Ram-Mohan, "Band parameters for III-V compound semiconductors and their alloys," Journal of Applied Physics, vol. 89, no. 11, pp. 5815-5875, 2001.

[16] A. Aly and A. Nasr, "Theoretical study of one-intermediate band quantum dot solar cell," International Journal of Photoenergy, vol. 2014, Article ID 904104, 10 pages, 2014.

[17] L. Cuadra, A. Martí, and A. Luque, "Present status of intermediate band solar cell research," Thin Solid Films, vol. 451-452, pp. 593-599, 2004. 
[18] F. Rahayu and Y. Darma, "Simulation of charge carriers generation rate of SiGe quantum dot based intermediate band solar cell," in AIP Conference Proceedings, pp. 203-206, 2012.

[19] S. Jenks and R. Gilmore, "Material selection for the quantum dot intermediate band solar cell," in Lecture Notes in Nanoscale Science and Technology, pp. 135-166, Springer, New York, NY, USA, 2013. 

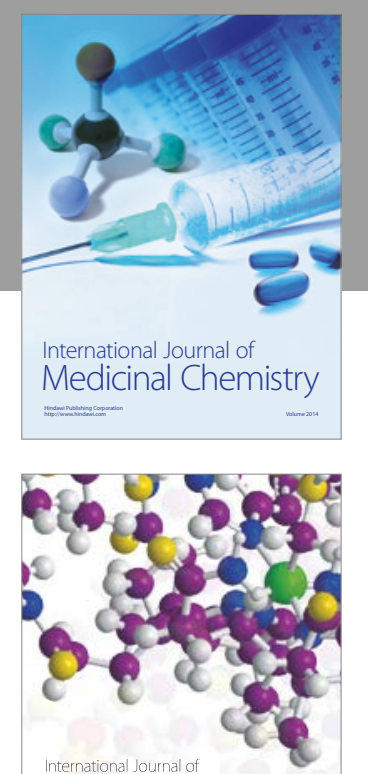

Carbohydrate Chemistry

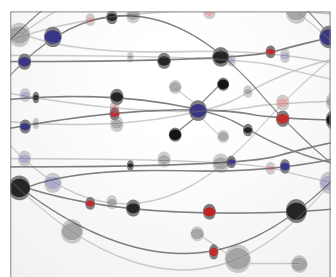

The Scientific World Journal
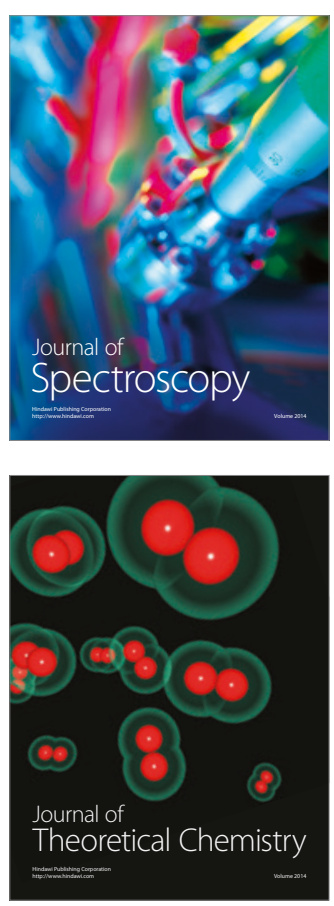
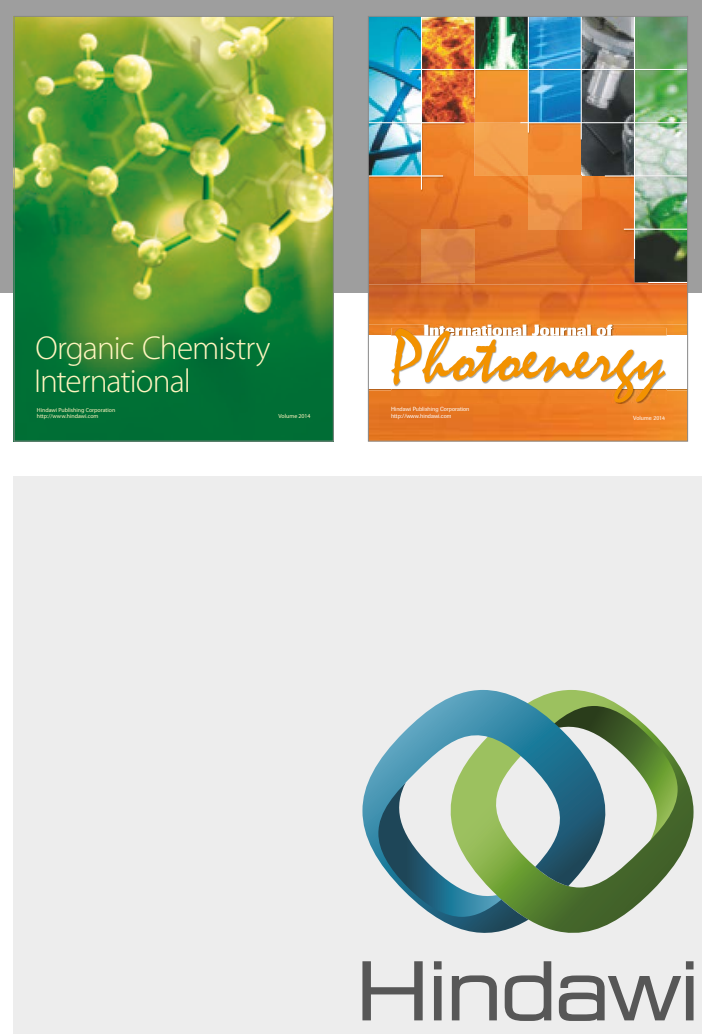

Submit your manuscripts at

https://www.hindawi.com

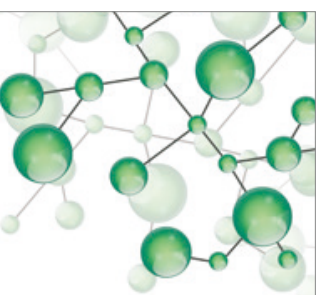

International Journal of

Inorganic Chemistry

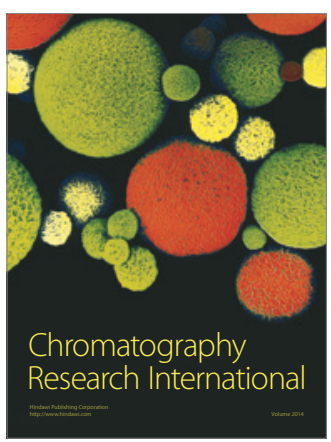

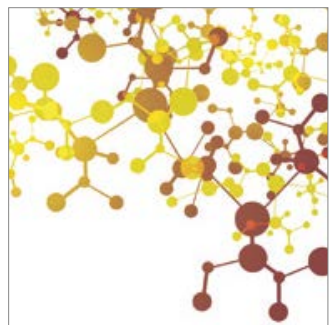

Applied Chemistry
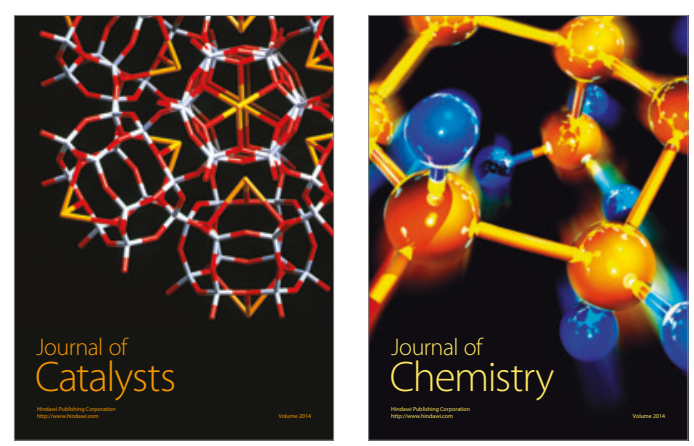
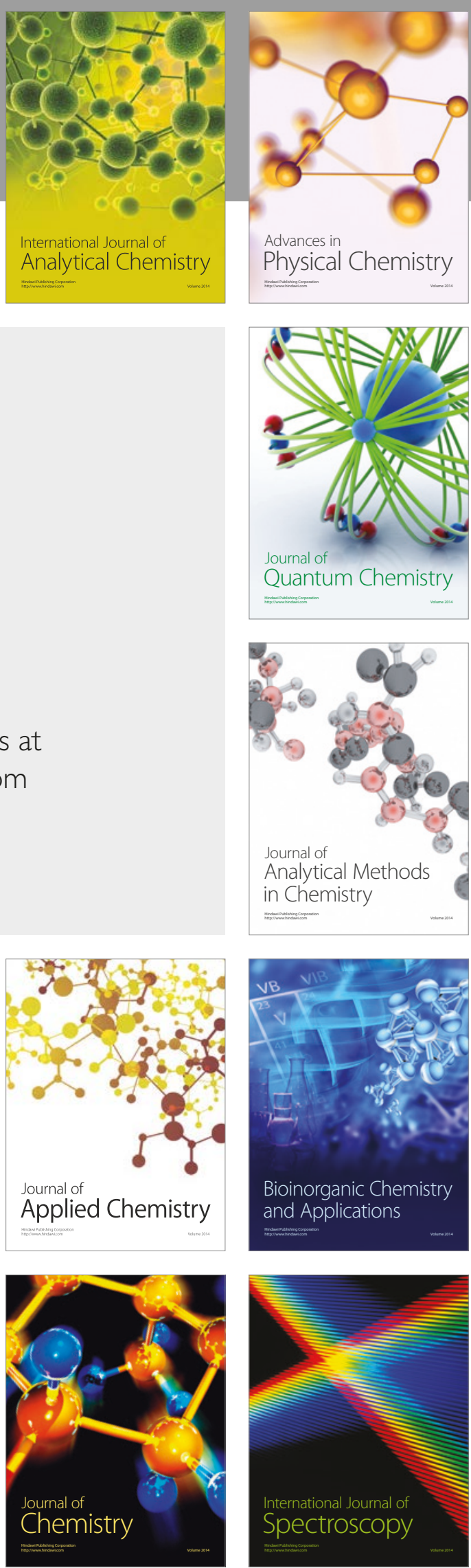